\title{
UCRL-JC-151432
}

\section{Measurements of the}

Radiated Fields and

Conducted Current Leakage

from the Pulsed Power

Systems in the National

Ignition Facility at LLNL

R. A. Anderson, T. J. Clancy, S. Fulkerson, D.

Petersen, D. Pendelton, S. Hulsey, G. Ullery, J.

Tuck, M. Polk, R. Kamm, M. Newton, W. B.

Moore, P. Arnold, C. Ollis, A. Hinz, C. Robb

July 31, 2003

$14^{\text {th }}$ Annual International Pulsed Power Conference Dallas, Texas, June 16-19, 2003 
This document was prepared as an account of work sponsored by an agency of the United States Government. Neither the United States Government nor the University of California nor any of their employees, makes any warranty, express or implied, or assumes any legal liability or responsibility for the accuracy, completeness, or usefulness of any information, apparatus, product, or process disclosed, or represents that its use would not infringe privately owned rights. Reference herein to any specific commercial product, process, or service by trade name, trademark, manufacturer, or otherwise, does not necessarily constitute or imply its endorsement, recommendation, or favoring by the United States Government or the University of California. The views and opinions of authors expressed herein do not necessarily state or reflect those of the United States Government or the University of California, and shall not be used for advertising or product endorsement purposes.

This work was performed under the auspices of the U.S. Department of Energy by University of California, Lawrence Livermore National Laboratory under Contract W-7405-Eng-48. 


\title{
MEASUREMENTS OF THE RADIATED FIELDS AND CONDUCTED CURRENT LEAKAGE FROM THE PULSED POWER SYSTEMS IN THE NATIONAL IGNITION FACILITY AT LLNL
}

\author{
R. A. Anderson, T. J. Clancy, S. Fulkerson, D. Petersen,D. Pendelton, S. Hulsey, G. Ullery, J. \\ Tuck, M. Polk, R. Kamm, M. Newton, W. B. Moore, P. Arnold, C. Ollis, A. Hinz, C. Robb, \\ J. Fornes, J. Watson \\ Lawrence Livermore National Laboratory \\ Livermore, California, USA
}

\begin{abstract}
An important pulsed power system consideration is that they inherently generate fields and currents that can cause interference in other subsystems and diagnostics. Good pulsed power design, grounding and isolation practices can help mitigate these unwanted signals.

During the laser commissioning shots for the NIF Early Light milestone at LLNL, measurements were made of the radiated field and conducted currents caused by the Power Conditioning System (PCS) modules with flash lamp load and the Plasma Electrode Pockels Cell (PEPC) driver. The measurements were made in the capacitor bay, laser bay, control room and target bay. The field measurements were made with B-dot and E-dot probes with bandwidth of about $100 \mathrm{MHz}$. The current measurements were made with a clamp on probe with a bandwidth of about $20 \mathrm{MHz}$.

The results of these measurements show fields and currents in the NIF Facility well below that required for interference with other subsystems. Currents on the target chamber from the pulsed power systems are well below the background noise currents.
\end{abstract}

\section{INTRODUCTION}

Detailed EMI noise studies have been done on the pulsed power systems that were designed for the NIF. These studies were done on the PCS and the PEPC test stands during the acceptance and life tests on sample pulsed power units. The results of those studies showed that the generated noise levels would be below that required for circuit upset and personnel hazard. Since the configuration of the pulsed power systems and the building grounding is somewhat different in the NIF than on the test stands, additional noise measurements were made during the startup of NIF. This paper describes the results of those measurements.

\section{NOISE SOURCES}

The PCS and the PEPC are the two major pulsed power sources of EMI generated noise in the NIF. The noise generation mechanisms are different in each unit. The noise generated by the PCS comes from the spark gap switch in the power supply unit and from the transition $\mathrm{f}$ from co-axial geometry to the flash lamp geometry at the laser amplifier. This transition is done in a large plastic connector, which is the top of the flash lamp line replaceable unit (LRU). The time history of a single lamp current pulse is shown in Figure 1. Each PCS supplies twenty pulses simultaneously. There is a pre ionization lamp conditioning pulse (PILC) prior to the main pulse. This pulse has a faster rise time due to LRC circuit considerations, which produces a higher amplitude $\mathrm{dI} / \mathrm{dt}$ $\left(\sim 10^{11} \mathrm{~A} / \mathrm{sec}\right)$. This is indicated by the red arrow on Figure 1. Measurements have shown that the noise amplitude is related to $\mathrm{dI} / \mathrm{dt}$. Laser light amplification occurs after the peak of the main pulse, there fore the noise generated by the PCS occurs several hundred micro seconds before laser light is present. Currently there are nine operational modules powering four laser beams. A fully operational NIF contains 192 lasers powered by 212 PCS.

The function of the PEPC is to switch out the laser pulse from the main multi pass amplifier to the power amplifier. The pulsed current delivered to the unit consists of a very long simmer pulse (300 Volts), a plasma pulse $(5 \mathrm{KV})$ and the switch pulse $(17.4 \mathrm{KV})$, which changes the plasma from reflection to transmission. It is shown schematically in Figure 2. The switch pulse is the dominant noise source during the pulse sequence. Measurements show that the EMI generated by the PEPC switch pulse has lower amplitude and higher frequency content than the PILC pulse.

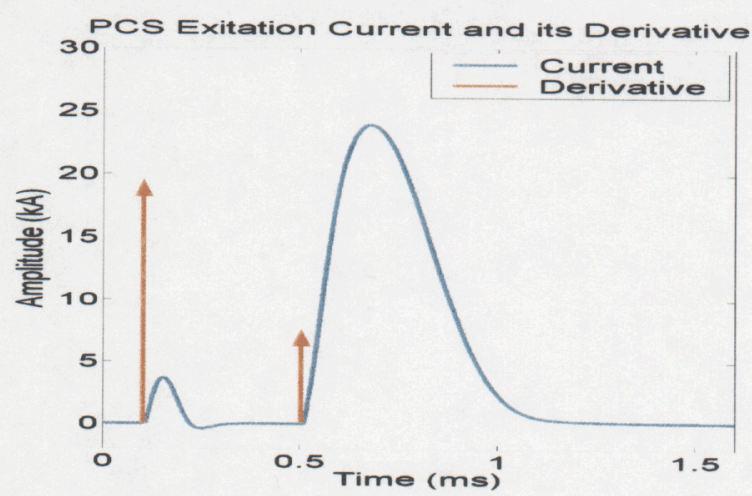

Figure 1. PCS excitation current and its derivative 


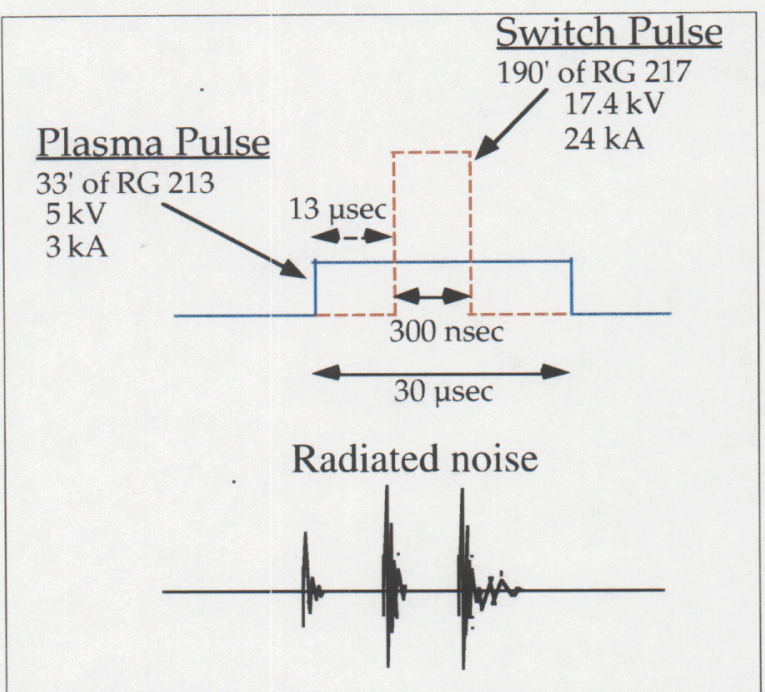

Figure 2. Schematic representation of the PEPC drive current.

\section{NOISE MITIGATION}

The NIF pulsed power system was designed to help mitigate EMI. The design considerations involved the construction of a very low impedance facility, the use of fiber-optic trigger and diagnostic lines, the use of EMI cable trays, racks, and cabinets and the implementation of electrical and physical isolation between the Laser Bays and the Target Bay.

Noise Mitigation was implemented in the PEPC by the use of coaxial cables to carry the drive power. The metal laser beam tubes provides shielding around the PEPC plasma switch. The Switch Pulse generator is housed in commercial grade EMI racks.

Noise Mitigation was implemented in the PCS and flash lamps by the use of coaxial cable to carry the flash lamp drive power. Leakage current from the non-coaxial termination at the flash lamps is returned through a low impedance EMI cable tray. The PCM's utilize steel enclosures made with machined surfaces and coax is used throughout in order to minimize the radiated EMI.

Facility Reinforcing Iron Bar (rebar) was densely packed within the floor of the NIF facility resulting in a very low impedance to the conducted and RF EMI. This construction is shown in Figure 3. Impedance measurements between the copper ground grid and rebar are typically a few $\mathrm{nH}$, which is sufficient evidence that they are electrically connected. Conductive isolation is achieved by the physical and electrical separation of the Laser Bays and the Target Bay. High-frequency EMI is blocked by $16 \mathrm{uH}$ of inductance through the J-tube which connects

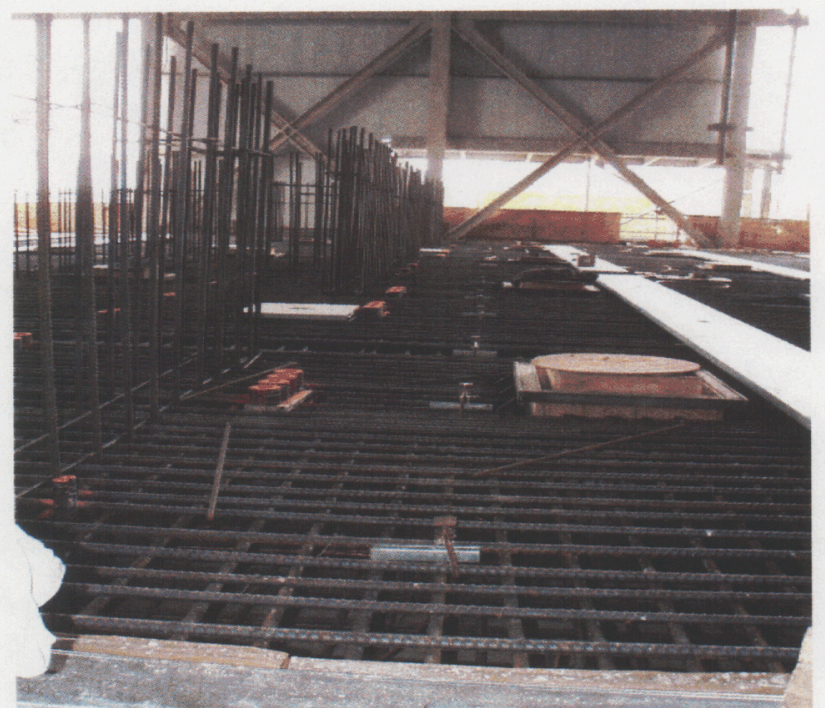

Figure 3. NIF building rebar density in construction.

the Laser Bays to the Target Bay. There is seismic isolating gap between the laser system floor and the rest of the building. This provides a high impedance path that keeps the conducted currents localized.

\section{MEASUREMENTS}

Electromagnetic field measurements were made during the NIF early light (NEL) commissioning shots. Measurements were performed in multiple locations in Laser Bay 2, Capacitor Bay 3, Target Bay, and the hallways outside the control room and other operations rooms.

The measurement sensors include B-dot and E-dot antennas, along with current probes. These devices provided a bandwidth of roughly 1 to $300 \mathrm{MHz}$. The sensor output is connected via a double shielded high bandwidth coaxial cable to a digital storage oscilloscope. Triggering is accomplished from the NIF master trigger source via a fiber optic link to avoid ground loops with the NIF system. Where practical, all measurement components were isolated from the NIF.

Target Bay conducted current measurementswere taken by synchronization of the Laser Bay RF EMI measurements and conducted current measurements on the Target Chamber legs. The measured EMI from the use of nine PCM's are below the noise. This, along with field measurements within Laser Bay 2, lead to the conclusion that field leakage into Target Bay from PCS is also below the noise.

\section{PROCESSED RESULTS}

In order to obtain the incident electric field $E_{\text {inc }}$, the sensor voltage is numerically integrated and scaled with the appropriate sensor scale factors. In the cases where only the peak electric field was of interest the data was passed through a $1 \mathrm{MHz}$ high pass filter, to simplify the numerical integration process. An example of the 


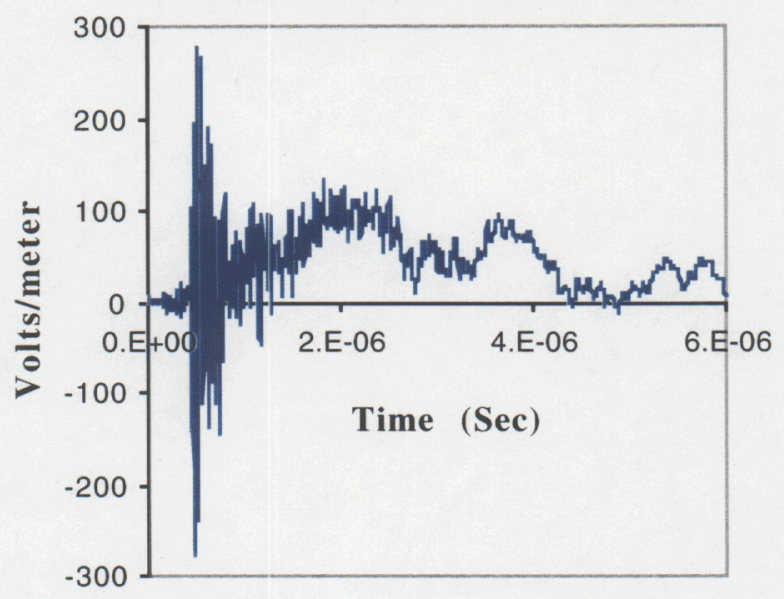

Figure 4. Radiated electric field from the PCS

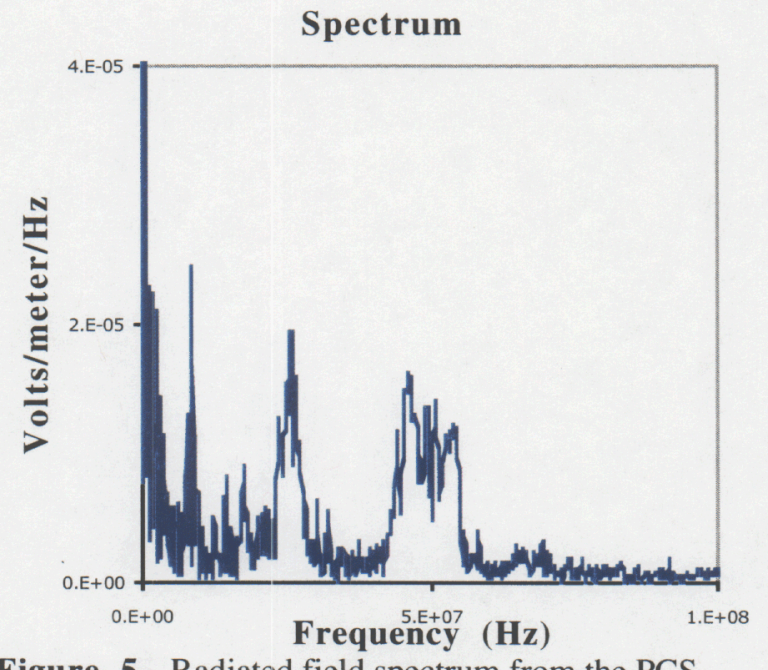

Figure 5. Radiated field spectrum from the PCS

processed data is shown in Figure 4 and 5. The B-field and E-field measurements agree.

The resulting measured fields due to the PCS and PEPC are summarized in Figure 6. Note that locations B, and $\mathrm{C}$ were taken approximately one meter from the flash lamps and result in the highest measured fields. Also note that the fields increase as addition source modules are added, however, the scaling is not linear. This presents a problem when trying to scale to a fully operational NIF comprised of 192 laser beams.

\section{SIMULATION}

It is necessary to be able to predict what the field and currents will be when additional pulsed power units are brought on line. To accomplish this task, an electromagnetic field simulation of PCS modules and flash lamps was performed based on image theory and the following simplifying assumptions. The PCS modules and cable terminations at the flash lamps are isotropic sources with the same temporal characteristic. The individual sources produce fields that fall of at the rate of $1 / r^{n}$, where $n$ is found from the measured data and in this case is equal to 1.7. The source electromagnetic fields are proportional to excitation $I(t)$, as shown in Figure 1. Coherent addition of fields is assumed which is only strictly valid below $300 \mathrm{KHz}$. This results in a very conservative estimate of field levels, and thus a solid upper bound is expected.

Due to spark gap jitter and shot to shot variation, the source frequency content above $2.5 \mathrm{MHz}$ is of random phase and amplitude. Therefore, future plans include refining the model to include incoherent addition of fields by use of probability and random processes theory. The model will then be extended to 192 beams.

The results of the simulation are shown in Figure 7. The contour plot is color coded in $\mathrm{dbV} / \mathrm{m}$ and the yellow labels have units of $\mathrm{V} / \mathrm{m}$. Measurements are also shown on this plot by color-coded squares.

\section{CONCLUSION}

The field measurements indicate that the NIF pulsed power design and installation has achieved relatively low radiated fields and conducted currents. The measured field strengths are well below personnel safety requirements and levels required for circuit upset. It is expected that noise from the pulse power will not degrade the diagnostic capabilities on the NIF. The noise generated from physics processes in the laser target interaction will be much higher than the noise from the pulsed power systems.

The spectrum of the radiated fields show resonances, some of which, can be attributed to the PCS physical size and transmission line lengths. The height of the PCS above the floor causes a quarter wave resonance at $25 \mathrm{MHz}$. The transmission line lengths will be resonant at much lower in frequency.

Additional work must be done to aid in the prediction of field levels as more laser beams are activated. 
Measurement locations on the NIF floor plan
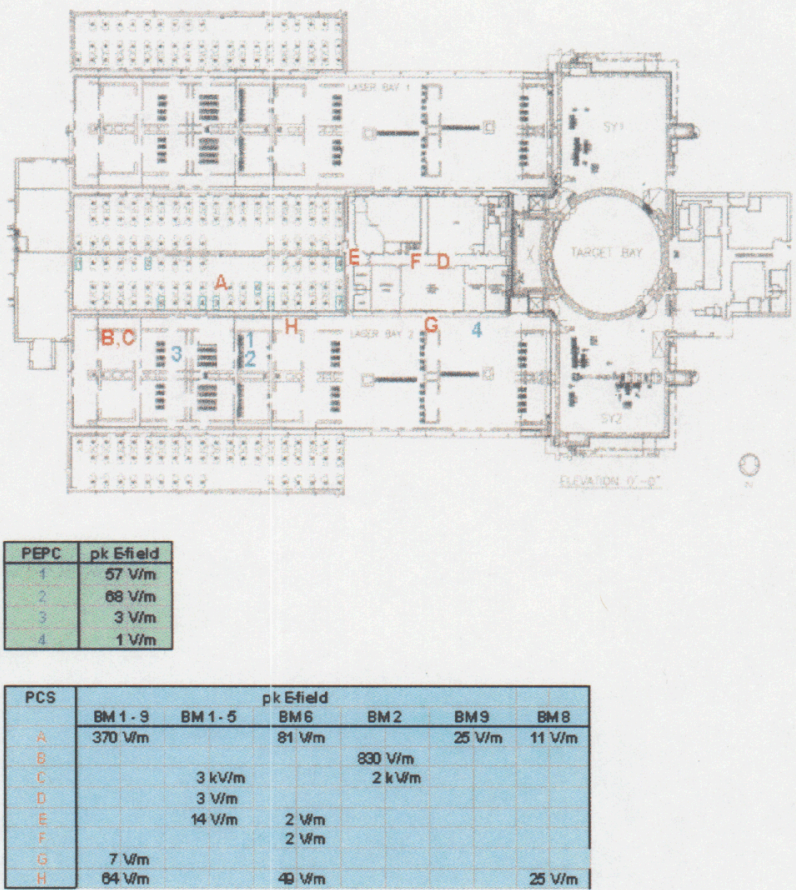

Figure 6. Measured electric field levels due to the PCS and PEPC.
Calculated and measured electric field levels in the NIF

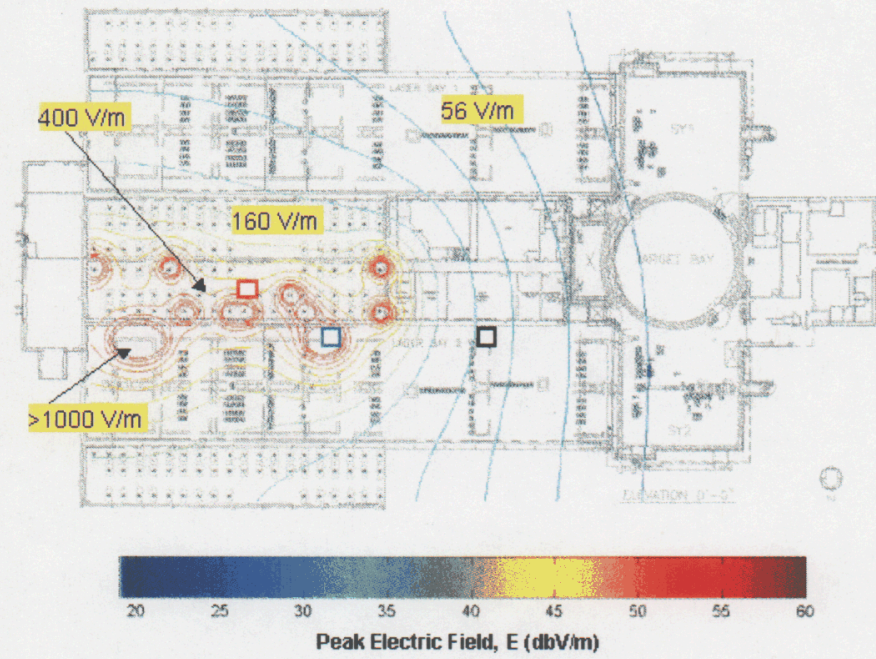

\begin{tabular}{|c|l|}
\hline \multicolumn{2}{|c|}{ Measurements } \\
\hline$\square$ & $370 \mathrm{Vim}$ \\
\hline$\square$ & $64 \mathrm{Vim}$ \\
\hline$\square$ & $7 \mathrm{Vim}$ \\
\hline
\end{tabular}

Figure 7. Simple simulation of electric field levels due to nine PCM's and non-coaxial terminations at flash lamps. 